\title{
Development of an Intelligent Teaching System Based on 3D Technology in the Course of Digital Animation Production
}

\author{
http://dx.doi.org/10.3991/ijet.v11i09.6116 \\ Yuanyuan $\mathrm{Ji}^{1}$, Yajuan Liu ${ }^{2}$ \\ ${ }^{1}$ Dalian Jiaotong University, Dalian, Liaoning, China \\ ${ }^{2}$ University of Science and Technology Liaoning, Anshan, Liaoning, China
}

\begin{abstract}
In recent years, with the rapid development of 3D digital technology based on computers and the Internet, human beings have realized visual, 3D observation of the real world. The visual, 3D characteristic of this technology completely conforms to the teaching objective of the digital animation course. Thus, it is profoundly and practically significant to develop an intelligent 3D teaching system and apply it in the course of digital animation production. Through using digital animation production as the experimental course, this study comparatively analyzed the different teaching effect of using the intelligent 3D teaching system in the course of digital animation production, and provided theoretical and statistical supports for the application of that system in the course of digital animation production and college education.
\end{abstract}

Index Terms-3D, digital animation production, intelligent teaching system, development

\section{INTRODUCTION}

The major of digital animation just started in colleges in recent years. According to relevant investigations, professional designers of digital animation featured by the mastery of audiovisual language, a solid foundation of painting, and the proficiency in operating computers and other related equipment are rare resources in the market [1]. The virtual feature of animation, a fantasy art, is shown not only in the extraordinary, unique, unstrained, and vigorous story, but also in the unconventional and exaggerated audiovisual style, specifically, reflected in the imaginary scene setting, virtual figure modeling, and transformation of sound elements [2]. Thus, the strong formal and unreal sense makes animation become the representative of fictional art.. Generally, the current teaching concerning digital animation fully and correctly interprets basic concepts and theories, but lacks a strong professional pertinence. Accordingly, the practical emphasis of teaching is placed on the explanation of basic theories, mostly using traditional film and television works to explain related concepts; due to the negligence of professional pertinence, it becomes considerably difficult to mark the teaching target, thereby affecting the effect of course teaching [3].

As a consequence of the mode of simulating real objects, 3D technology could be effectively used in the construction of an intelligent teaching system [4]. The application of 3D technology in teaching and research and of digital animation production can provide more abundant channels for teaching, enhancing effect of teaching and improving teaching quality. The current teaching system that uses $3 \mathrm{D}$ technology can meet the experimental requirements such resource downloading and job submission, contributing to teaching to some extent [5]. At present, among all intelligent teaching systems, the intelligent $3 \mathrm{D}$ teaching system is the most popular development direction [6]. In a teaching experiment, McMenamin proposed that when illustrating the contrast $\mathrm{CT}$ radiographic data utilizing segmentation software and comparing the accuracy of printed specimens with original specimens, this alternative method of anatomically creating accurate reproductions would show more advantages over plastination; this approach should be suitable for any teaching facility in any nation since it allows fast production of multiple copies of any dissected specimen at any size scale, thereby avoiding some ethical and cultural issues regarding cadaver specimens either in a plastinated or embalmed form [7]. Lan [8] constructed a virtual language environment with 3D technology and applied it in language teaching. The positive results obtained from the study approved that students can enjoy learning opportunities in EFL learning without time and space limits because of the usage of virtual contexts. In 2010, Wang et al. [9] designed and investigated the teaching system of the 3D animation design course according to the practical needs of a college, analyzed the characteristics and shortcomings of the system, and came up with the application value of the system in the teaching process. Scalfani and Vaid [10] tried to use 3D printing technology in chemical courses and discussed suitable routes in preparing 3D printable digital files of chemical structures in this study. Furthermore, they also suggested that $3 \mathrm{D}$ printing is an excellent method for fabricating 3D models of molecules and extended solid.

However, the old intelligent teaching system has obvious shortcomings in humanization of its interface, teacher-student interaction, and preciseness of design flow. Thus, teachers can only teach with continuous demonstrations, making it difficult for students to completely understand digital animation production. Moreover, the intelligent 3D and non-3D teaching systems tend to be uniform in form and application effect, meaning that the former does not show remarkable characteristics. This research innovatively proposed the construction of a humanized and highly interactive intelligent $3 \mathrm{D}$ teaching system. The projection style of the $3 \mathrm{D}$ display device can provide teachers and students with higher quality teaching experience, and enhance students' learning consciousness and initiative. Meanwhile, the function and inadequacies of the 
teaching system in teaching effect and experience obtained through the comparative experiment can be gathered to provide guidance for future teaching practices.

\section{Design Of The INTELLIGENT 3D TEACHING SYSTEM}

The intelligent 3D teaching system aims to provide learners with real-time, effective, and comprehensive learning with the help of a computer system [4]. In addition, the intelligent 3D teaching system consists of two parts, respectively the hardware environment and the core courseware. The hardware environment refers to the virtual reality system, including the projection-style $3 \mathrm{D}$ device and its colorized display. The software part is mainly composed of the $3 \mathrm{D}$ teaching courseware, which is closely related to teacher-student interactive operations in the classroom. Designs of the intelligent 3D teaching system include the module, hardware, and function. This study analyzed the three design aspects respectively by combining with characteristics and requirements of the course of digital animation production.

\section{A. System Module Design}

According to the shortcomings in the past teaching systems and students' need, the intelligent 3D teaching system in this research covers course construction, theoretical teaching, practical teaching, learning exchange, auxiliary resources, and other major modules.

The module of course construction includes course introduction, teaching plan, system, and expansion. The unit of theoretical module, which can realize the download of teaching resources, incorporates electronic courseware, teaching progress, important and difficult points, and after-class exercises. The module of practical teaching, which ensures the orderly process of a course experiment, consists of questions and answers about knowledge points, work download, and course work collection. The module of auxiliary resources contains appreciation and analysis of works, as well as exquisite materials, which can help students further optimize their experimental design works. Figure 1 shows the schematic diagram of the overall 3D teaching system, including control templates of the central control system, 3D server, 3D projector, resources of 3D teaching software, processing system of the 3D synchronizing signal, central control system, audio system, and $3 \mathrm{D}$ classroom.

\section{B. System hardware design}

Hardware design of the intelligent 3D teaching system can be realized based on one type. The 3D display device is made up of the directional light source, projector, directional projection screen, and other parts. The diagram of the overall structural frame is shown in figure 2.

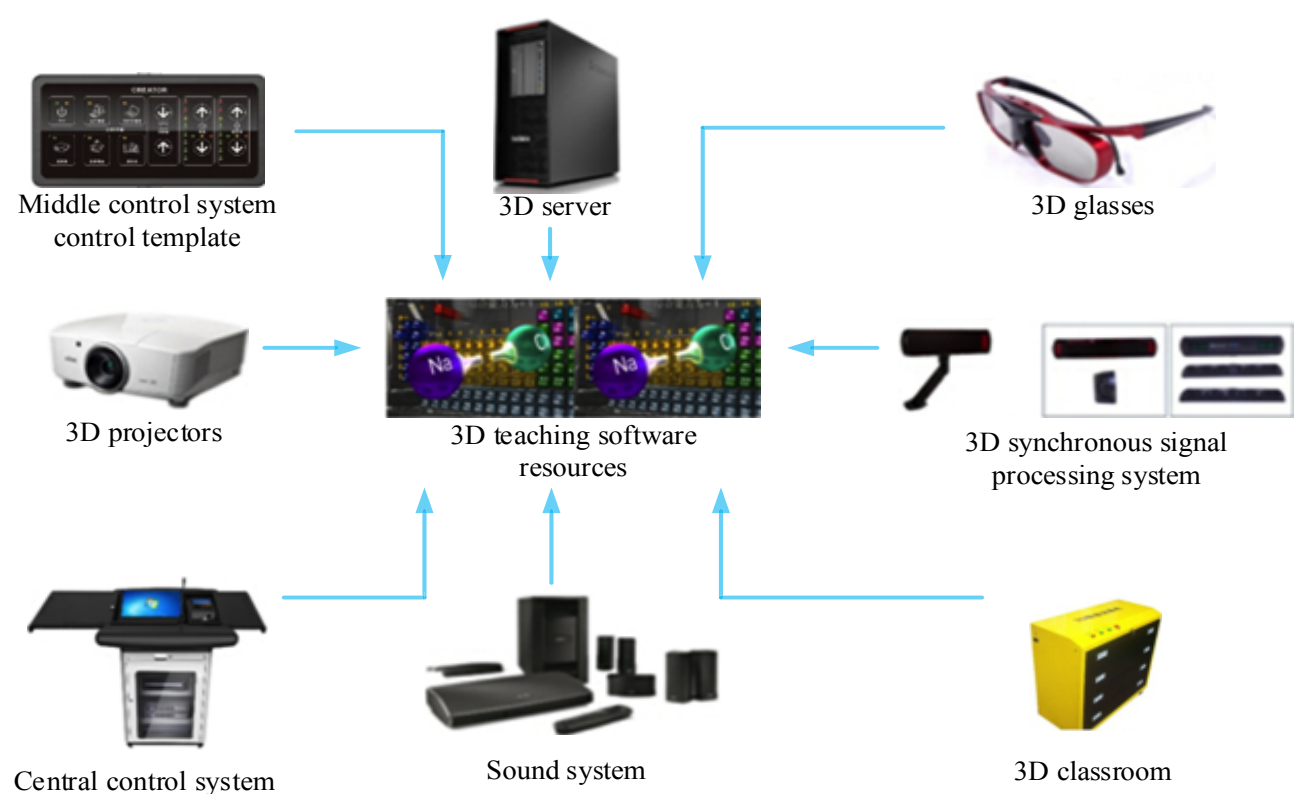

Figure 1. Schematic diagram of the overall 3D teaching system

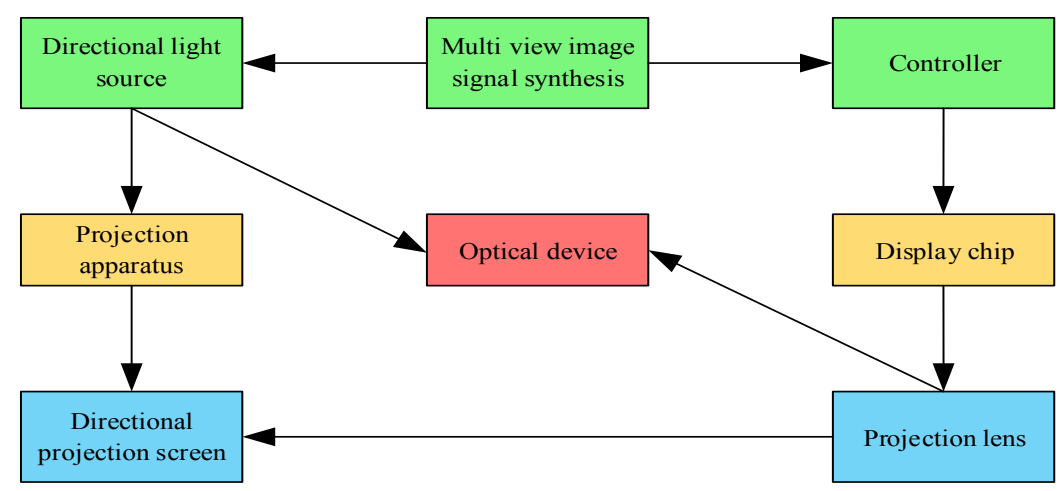

Figure 2. Diagram of overall structural frame of the system hardware 


\section{SHORT PAPER}

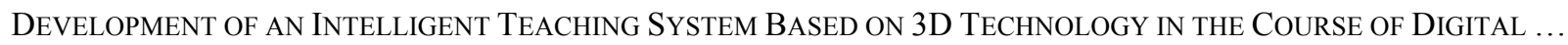

\section{System function design}

The intelligent 3D teaching system combines two functions, namely 3D visual-virtual technology and intelligent interaction. According to actual needs and module design, function of this system is designed in the following way: (1) browsing of courses and experiment conditions; (2) downloading of all sorts of teaching resources; (3) exchanging of questions and answers between teachers and students online; (4) uploading and sharing of students' works; and (5) assignment and viewing of homework.

Figure 3 shows the diagram of functional structure of the intelligent 3D teaching system. Figure 4 and 5 show the interface of the intelligent 3D teaching system during its practical application in the course of digital animation production.

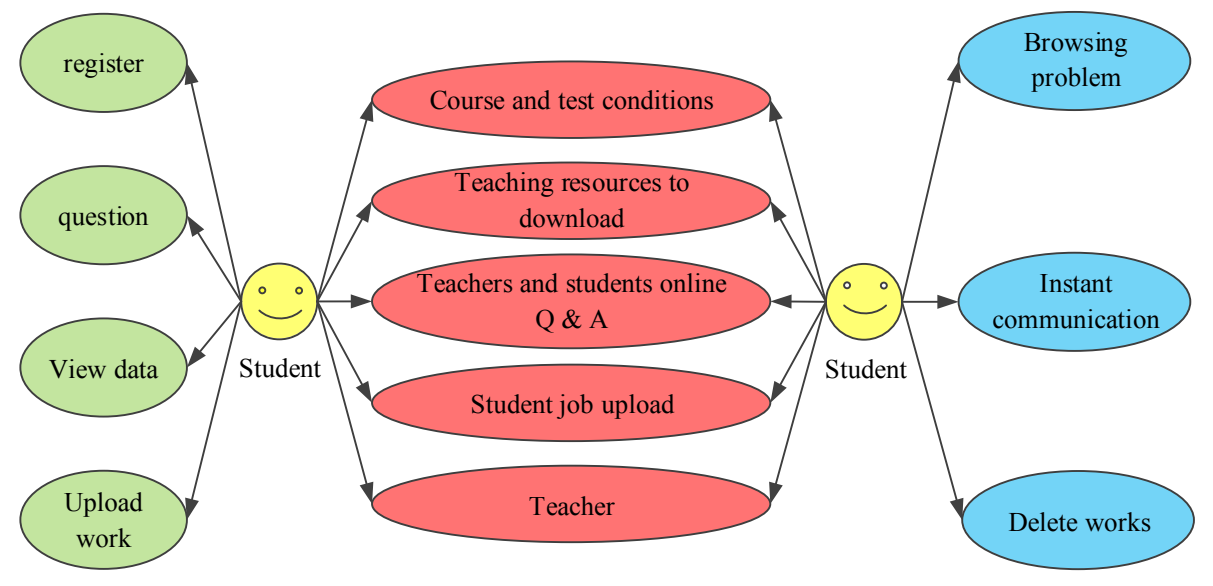

Figure 3. Diagram of functional structure of the system

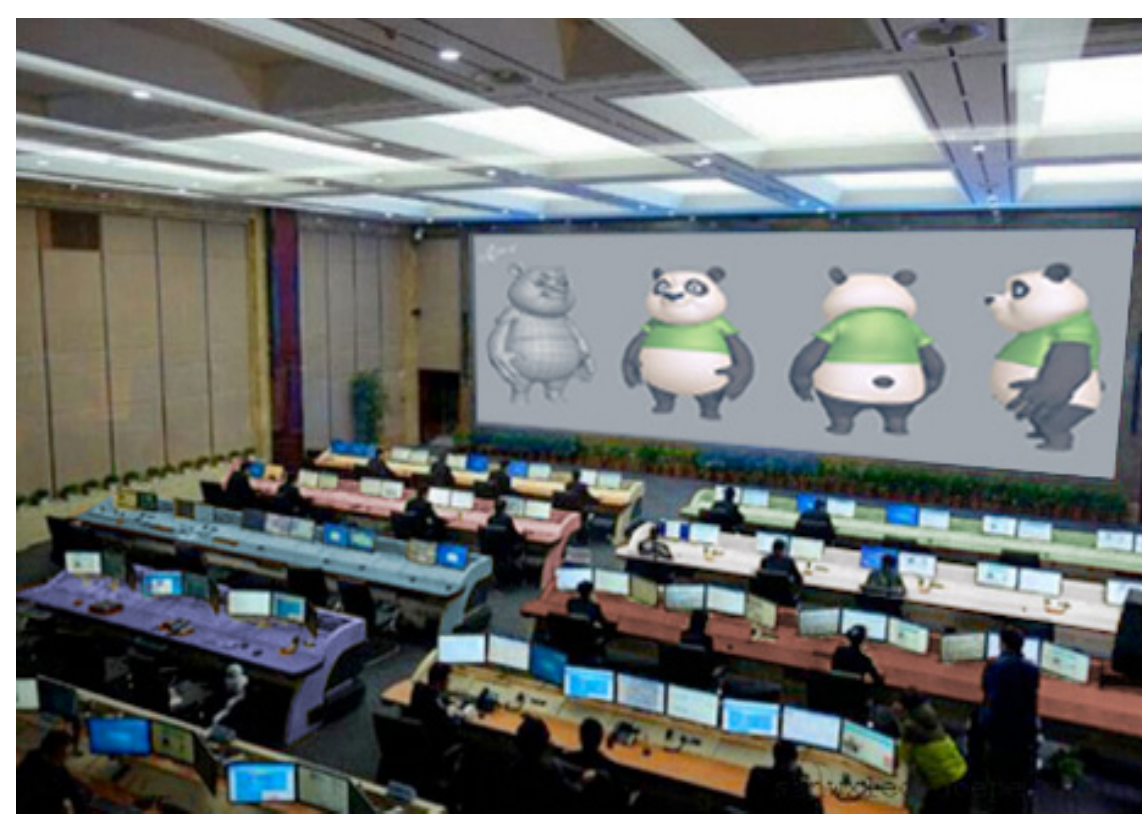

Figure 4. Diagram for interface of 3D intelligent teaching system

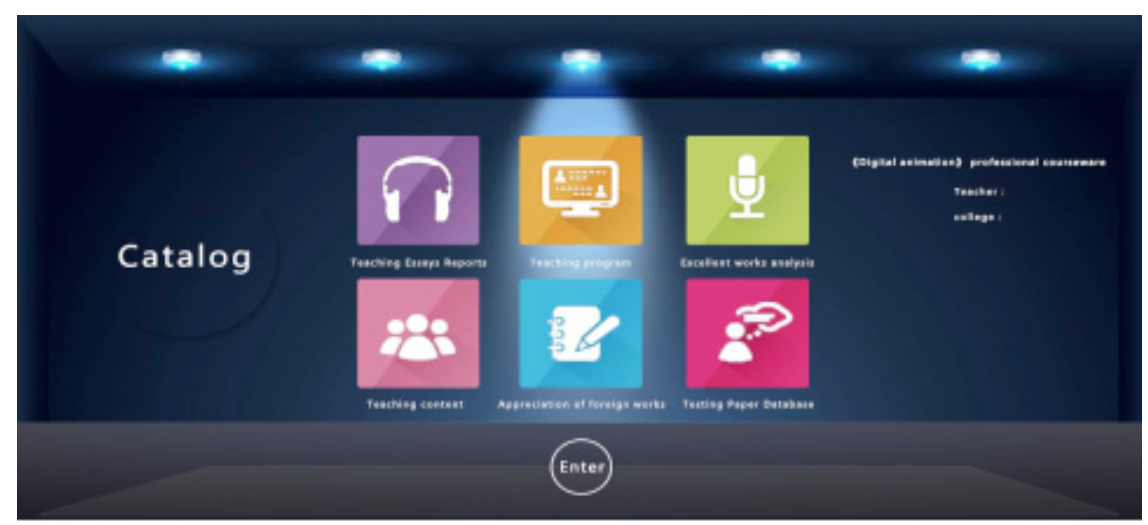

Figure 5. Diagram for interface of 3D courseware of 3D intelligent teaching system 


\section{EXPERIMENTAL DESign Of THE APPLICATION OF 3D InTElligent Teaching System In The Course OF Digital ANIMATION PRODUCTION}

As a key course of animation design major, digital animation production has a high degree of participation from students, thereby meeting the need of experiment implementation. The students enrolled in digital animation production need to have not only complete theoretical knowledge, but also high-level practical ability and professional skills. As shown in related investigations, students could independently realize basic functions of the intelligent 3D teaching system, so that the experiment could be conducted normally.

\section{A. Research Objects}

Digital animation production is the targeted course of this experiment. The course is generally scheduled in the sophomore year, with a total of 48 academic hours. The experimental objects are two undergraduate classes majoring in animation design, totally 110 students, with 58 persons in the experimental group, and 65 in the control group. Both groups had the same teachers and teaching conditions, and those students do not have any significant difference in age, gender, and academic performance. The learning content included theory and practice. After the end of the academic hours, a comparative analysis was conducted on the experimental and the control group. The collaboration between the researchers and the practitioners was the foundation for orderly implementation of the experiment.

\section{B. Research Methods}

\section{1) Control experiment method}

The traditional teaching system and method dominated by classroom teaching with textbooks as its basis was adopted in the control group. In addition, the learning content for students in the control group was dominated by theoretical knowledge. As for the practical course, the traditional computer system was used. Their homework was similar with that of the experimental group, and students could keep in touch with their teachers by the basic means of communication.

Conversely, the intelligent 3D teaching system was adopted in the experimental group. Teachers and students engaged in classroom activities through the system and promoted the teaching effect by taking full advantage of various functions of the system. Besides, during the experimental process, teachers could exhibit digital animation, issue teaching resources, assign homework, and answer questions online through the system. Meanwhile, students could learn, view their homework, and give timely feedback online in the system. Moreover, they could proficiently use the intelligent 3D teaching system for learning.

\section{2) Statistical method}

Experimental data were gathered and systemized via Microsoft Excel 2010 and analyzed by using SPSS 13.0 statistical software. The $t$ test of independent samples was used to compare quantitative data of the two groups. Experimental data were collected and recorded by the professional staff to guarantee accuracy of recording.

\section{Assessment of Teaching Effect}

Experiment result of using intelligent 3D teaching system in the course of digital animation production was concluded mainly through assessment on teaching effect. Specifically, teaching assessment was primarily performed through a questionnaire and classroom tests.

\section{3) Questionnaire}

After each class, students gave their feedbacks about learning effect in the intelligent 3D teaching system. After the course was finished, students would fill in the questionnaire based on the practical condition to guarantee validity of the investigation result. The questionnaire includes questions concerning students' interest, teaching effect, operability, image authenticity, and interest level. The highest and lowest score of each item were 10 and Orespectively. Anonymous grading was used to understand students' evaluation on different teaching methods.

\section{4) Classroom tests}

After a chapter was finished, 10 representative test questions were selected for assessment of teaching effect. The highest and lowest score of each question were 10 and 0 respectively. The ten questions include four questions concerning basic knowledge, 4 regarding important and difficult points, 1 about practical operation, and 1 for expansion. In the middle and end of the semester, students also needed to review sufficiently and then participate in relatively formal exams. Comparison of their exam results would reveal the difference in teaching effect.

\section{EXPERIMENTAL RESULT OF USING 3D INTELLIGENT TEACHING SYSTEM IN THE COURSE OF Digital ANimation Production}

In the experiment, 110 copies of the questionnaire were answered and collected. The statistical result of the questionnaire are shown in figure 6.

Figure 6 shows that compared with the traditional teaching system, the 3D teaching system has significant advantages in enhancing learning interest, strengthening teaching effect, operability, image authenticity and interest level, and other aspects $(\mathrm{p}<0.001)$. It can be seen that there are significant differences in image authenticity and interesting level. Students in the experimental group spoke highly of the function of the intelligent 3D teaching system in enhancing their learning interest. In addition, the operability of the intelligent $3 \mathrm{D}$ teaching system still needs improvement, because some students felt unsatisfied with the affinity of the operational interface.

The comparison of scores of classroom tests is shown in figure 7.

Figure 7 shows that the overall score of students in the experimental group in the four test modules is higher than that of their counterparts in the control group. The differences in scores of three modules, including basic knowledge, important and difficult points, and experimental operations are statistically significant $(\mathrm{p}<0.001)$. As for the total test score, the experimental group surpassed the control group, showing significant advantages $(p<0.001)$. With assistance of the intelligent 3D teaching system, the effect teaching important and difficult points and practical operations was improved significantly, re- 


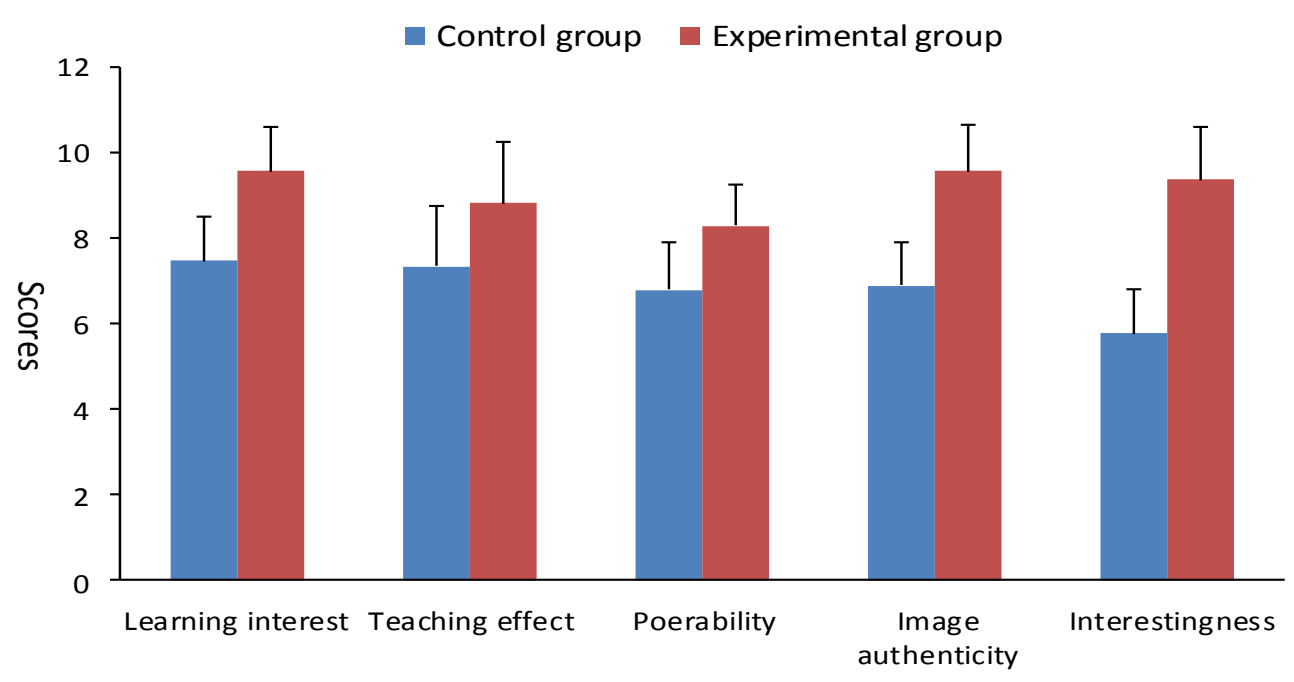

Figure 6. Statistical table of the result of questionnaire

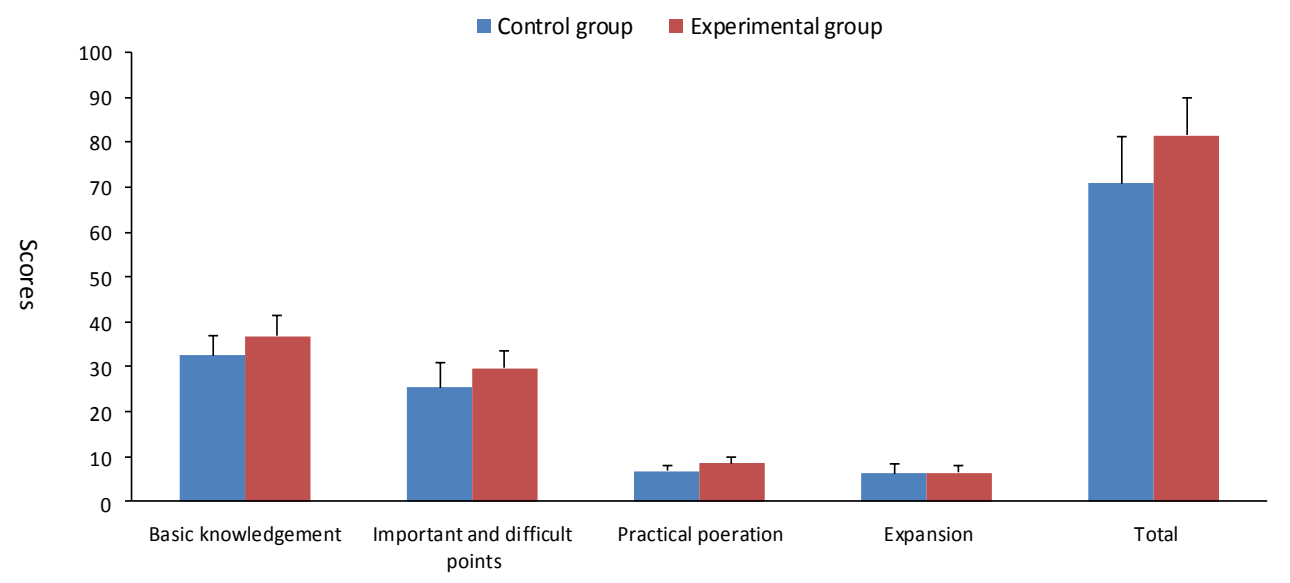

Figure 7. Statistical table of classroom test scores

sulting in the rise of students' scores to a large extent. However, the issue of inadequate expansion in the intelligent 3D teaching system should be improved urgently. The comparison between the experimental and the control group in terms of expansion does not reveal a significant difference $(\mathrm{p}=0.653)$, which indicates that students can only obtain limited knowledge expansion from the intelligent $3 \mathrm{D}$ teaching system. Thus, it is necessary to further enrich content of the system.

As shown in the research, the intelligent 3D teaching system is considerably popular among students and has a promising application prospect in real-time learning and intelligent questions and answers. Moreover, it will certainly become the mainstream mode of the course of digital animation production and college teaching. The intelligent 3D teaching system can be applied during and after class of course teaching. In class, teachers can exhibit teaching resources and stimulate students' learning interest through the projection-style 3D device and its colorized display. With the system, teachers can easily master students' learning progress and thus prepare more suitable content of practical operations and theoretical practices for students. Moreover, students can apply classroom knowledge rapidly and strengthen their knowledge reception. As for enhancement of learning interest, image authenticity, and interest level, the effect of applying the intelligent 3D teaching system is more impressive. However, the effect of classroom teaching should still be further improved. After class, teachers and students can still interact with each other in a convenient and fast manner. Students can download related materials, raise questions, upload their work, browse question records, and complete the content expansion through this system. Teachers can learn students' real-time tendency, continuously adjust the teaching objective, and achieve a better teaching effect. Application of the intelligent 3D teaching system can help students significantly enhance their academic results. However, there are still more room for the improvement of these academic results. In other words, it is required to constantly optimize the system for achieving more significant effects. With the continuous renewal and optimization of the intelligent 3D teaching system, characteristic functions, such as massive database and targeted teaching, will be more suitable for practical teaching. This will make significant contributions to reduction of teachers' and students' burdens and optimization of teaching effect in the future. 


\section{CONCLUSION}

The intelligent $3 \mathrm{D}$ teaching system designed in this study is characterized by high affinity of its operation interface and strong interaction. Based on the principle of unification and segmentation for design of the system webpage, its interface looks attractive and concise. The system does not only realize human-computer interactions, but also further realizes interpersonal interactions, especially between teachers and students. In addition, it can fully utilize teaching resources to build channels for the exchange between teaching and learning. Furthermore, the intelligent $3 \mathrm{D}$ teaching system can store the overall 3D animation design modes, all sorts of teaching resources, and students' excellent works in the system's database and strengthen teaching effect with the assistance of computer technology. Then, we can realize the goal of reforming teaching mode and improving teaching quality in all teaching links by using functions of the intelligent 3D teaching system. In general, diversified forms and contents of the intelligent 3D teaching system can better improve teaching effect. They can also help students master the overall modeling thinking more completely and then make corresponding models in accordance with corresponding design requirements and drafts. Therefore, the intelligent $3 \mathrm{D}$ teaching system enjoys a wide application prospect, can exert its positive influences and effects in education and teaching, and has a high promotional value simultaneously.

\section{REFERENCES}

[1] Vaughn N.A., Jacoby S.F., Williams T., et al., "Digital Animation as a Method to Disseminate Research Findings to the Community Using a Community-Based Participatory Approach," American Journal of Community Psychology, vol. 5, no. 1-2, pp. 30-42, March 2013. http://dx.doi.org/10.1007/s10464-012-9498-6

[2] Hoyek N., Collet C., Rienzo F.D., et al., "Effectiveness of threedimensional digital animation in teaching human anatomy in an authentic classroom context," Anatomical Sciences Education, vol. 7, no. 6, pp. 430-437, March 2014. http://dx.doi.org/10.1002/ase.1446

[3] Flores R.L., Demoss P., Klene C., et al., "Digital animation versus textbook in teaching plastic surgery techniques to novice learn- ers," Plastic \& Reconstructive Surgery, vol. 132, no. 1, pp. 101e$109 \mathrm{e}$, July 2013. http://dx.doi.org/10.1097/PRS.0b013e3182 910aa9

[4] Wang R, Yang D., Li S., "Three-dimensional virtual model and animation of penile lengthening surgery," Journal of Plastic Reconstructive \& Aesthetic Surgery Jpras, vol. 65, no. 10, pp. 281285, October 2012. http://dx.doi.org/10.1016/j.bjps.2012.04.015

[5] Yu Y.G., Li Y., Cai J.Y., "Exploration and practice of 3D rendering animation in the teaching for the specialty of environmental art design in higher vocational colleges," The Science Education Article Collects, no. 19, pp. 153-154, July 2010.

[6] Van d.K.T., Dos S.R.T., Vagovič P., et al., "Three-dimensional reconstructions come to life--interactive 3D PDF animations in functional morphology," Plos One, vol. 9, no. 7, pp. e102355e102355, July 2014. http://dx.doi.org/10.1371/journal.pone .0102355

[7] Mcmenamin P.G., Quayle M.R., Mchenry C.R., et al.. "The production of anatomical teaching resources using three-dimensional (3D) printing technology," Anatomical Sciences Education, vol. 7, no. 6, pp. 479-486, December 2014. http://dx.doi.org/10.1002/ ase. 1475

[8] Lan Y.J., "Contextual EFL Learning in a 3D Virtual Environment," Language Learning \& Technology, vol. 19, no. 2, pp. 1631, June 2015.

[9] Wang W., Chen M.L., Hu J., "Research and application of the teaching system of 3D animation design course," The Science Education Article Collects, no. 31, pp. 35-36, November 2010.

[10] Scalfani V.F., Vaid T.P., "3D Printed Molecules and Extended Solid Models for Teaching Symmetry and Point Groups," Journal of Chemical Education, vol. 91, no. 8, pp. 1174-1180, August 2014. http://dx.doi.org/10.1021/ed400887t

\section{AUTHORS}

Yuanyuan Ji is a Lecturer at Dalian Jiaotong University, Dalian 116028, Liaoning, China. Her research interests include 3D Technology and Digital Animation Production. (zhangshengfang1973@163.com)

Yajuan Liu (Corresponding author) is a lecturer at University of Science and Technology Liaoning, Ansha 114051, China. Her research interests include virtual classroom and distance education (yajuanliu11@yeah.net)

Submitted 07 August 2016. Published as resubmitted by the authors 12 September 2016. 